\title{
Antibiofilm activity of epoxy sealer incorporated with quaternary ammonium macromolecule
}

\author{
Tal Becker ${ }^{1,6^{*}}$ (D), Nir Sterer ${ }^{2}$, Ronit Bar-Ness Greenstein ${ }^{3}$, Tamar Toledano ${ }^{4}$ and Michael Solomonov ${ }^{5}$
}

\begin{abstract}
Background: A common reason for failure of root canal treatment is residual bacterial biofilm or reinfection due to coronal seal inadequacy. Recently, the idea of using macromolecules with antibacterial features has evolved. The addition of nanoparticle macromolecules to sealers gained antibiofilm properties as shown in several in vitro studies. Nevertheless, no technique has yet been able to completely eliminate the residual biofilm. We evaluated the in vitro antibacterial effect of epoxy sealer, BJM ROOT CANAL SEALER ${ }^{\circledast}$ (BJM Laboratories Ltd., Or-Yehuda, Israel), incorporated with non-nanoparticle quaternary ammonium macromolecule (BIOSAFE HM4100, Pittsburg, PA, USA) against existing biofilm of Enterococcus faecalis and its ability to inhibit it de-novo.
\end{abstract}

Methods: Six mm diameter discs of epoxy sealer (BJM) incorporated with various concentrations of immobilized ammonium particles $(0,0.4,0.8,1.6$, and $3.3 \% \mathrm{~W} / \mathrm{V})$ were tested for its antibacterial effect on de-novo biofilm formation (by Biofilm Formation assay), and on existing biofilm (by Biofilm Viability assay). The Live/Dead bacterial ratio was determined using fluorescence microscopy.

Results: Biofilm formation assay showed significant reductions in de-novo biofilm formation of 25 and $72 \%$ in the higher ammonium particle concentrations of 1.6 and $3.3 \% \mathrm{w} / \mathrm{V}$ respectively $(p<0.001$ for both). Biofilm viability assay showed significant reductions in existing biofilm viability of 20 and $36 \%$ in the higher ammonium particle concentrations of 1.6 and $3.3 \% \mathrm{w} / \mathrm{V}$ respectively ( $p<0.001$ for both).

Conclusions: Biosafe incorporated in epoxy root canal sealer discs showed a pronounced reduction of de-novo biofilm formation in the higher concentrations ( 1.6 and $3.3 \% \mathrm{~W} / \mathrm{v}$ ), as well as some antibacterial effect against existing biofilm of $E$. faecalis. This sealer may be effective for prevention of de-novo formation of bacterial biofilm in treated root canals.

Keywords: Epoxy sealer, Macromolecule, Quaternary ammonium

\section{Background}

Bacteria play an essential role in initiation, progression, and persistence of apical periodontitis (Möller et al. 1981; Kakehashi et al. 1969). In the last decades, it has been shown that intracanal bacteria are organized in a biofilm which enables higher resistance to both antimicrobial agents and host defense mechanisms (Gilbert et al. 1997; Costerton et al. 1994; Costerton et al. 1987). Complete elimination of the biofilm from an infected

\footnotetext{
* Correspondence: toolik@gmail.com

${ }^{1}$ Department of Endodontology, Goldschleger School of Dental Medicine, Tel Aviv University, Tel Aviv, Israel

${ }^{6}$ Qiryat Ono, Israel

Full list of author information is available at the end of the article
}

root canal is usually not achievable by applying the common techniques (Fransson et al. 2013; Sadık et al. 2013; Cardoso et al. 2008; Huth et al. 2009; Hülsmann et al. 2003; Vianna et al. 2006; Nair et al. 2005; Peters et al. 2010; Peters 2004). Mechanical preparation is unable to reach all root canal walls (Peters et al. 2010; Peters 2004). The various irrigation protocols, including agents such as $\mathrm{NaOCl}$ (Nair et al. 2005), CHX (Vianna et al. 2006), EDTA (Hülsmann et al. 2003), the usage of Ozone (Cardoso et al. 2008; Huth et al. 2009), and direct and indirect laser irradiation (Fransson et al. 2013; Sadık et al. 2013) were also unable to achieve a sterile canal. 
A common reason for failure of root canal treatment is residual bacterial biofilm or reinfection due to coronal seal inadequacy (Nair 2014), (Ray and Trope 1995).

Recently, the idea of using macromolecules with antibacterial features has evolved (Kenawy et al. 2007; Barros et al. 2014; Kesler Shvero et al. 2013; Shrestha et al. 2010; Kishen et al. 2008). The addition of nanoparticle macromolecules to sealers gained antibiofilm properties as shown in several in vitro studies (Barros et al. 2014; Kesler Shvero et al. 2013).

A new concept is suggested by adding of non-nanoparticle macromolecules with antibiofilm features (Biosafe ${ }^{\circ}$, HM4100, BIOSAFE Inc., Pittsburg, PA, USA) to epoxy sealer. BioSafe ${ }^{\bullet}$ has received FDA approval (Application number 292 from December 12th 2013) and is based on a Silane quaternary ammonium salt. It has already been used as an additive to plastic devices such as catheters and keypad covers in order to prevent biofilm formation (D'Antonio et al. 2013).

The aim of the present study was to test the in vitro antibacterial effect of epoxy sealer BJM ROOT CANAL SEALER $^{\circ}$ (BJM Laboratories Ltd., Or-Yehuda, Israel), incorporated with non-nanoparticle macromolecules (BioSafe ${ }^{\oplus}$, HM4100, BIOSAFE Inc., Pittsburg, PA, USA) against existing biofilm of Enterococcus faecalis and its ability to inhibit de-novo biofilm formation of Enterococcus faecalis.

\section{Methods}

\section{Tested materials preparation}

The tests specimen discs $(6 \mathrm{~mm}$ diameter and $3 \mathrm{~mm}$ thickness) were prepared utilizing a split Silicon molds. Prior to the specimen's preparation, Vaseline was applied over the mold to prevent dripping and to ease sample removal. The sealer was syringed directly from the auto-mix syringe into the mold cavities utilizing a plastic mixer. The surfaces of the discs were flat and even. The discs were kept for $24 \mathrm{~h}$ in a dry oven (laboratory incubator) constantly maintained at $37{ }^{\circ} \mathrm{C}$ to allow setting. Afterwards, the discs were emerged in water for $24 \mathrm{~h}$ at the oven (laboratory incubator) constantly maintained at $37^{\circ} \mathrm{C}$.

Six discs of epoxy sealer (BJM) incorporated with various concentrations of immobilized quaternary ammonium particles $(0.4,0.8,1.6,3.3 \% w / v)$ or without any addition (as negative control) were prepared and sterilized by autoclaving.

Bacteria and growth conditions: Enterococcus faecalis (ATCC 51299) was subcultured for $48 \mathrm{~h}$ in brain heart infusion (BHI) broth (Difco) at $37{ }^{\circ} \mathrm{C}$ under aerobic conditions.

\section{Biofilm formation assay}

Tested material discs were placed at the bottom of a 96-well microplate. Discs were inoculated with $20 \mu \mathrm{L}$ of the tested bacterial suspensions (1.0 OD, $600 \mathrm{~nm}$ ) and allowed to adhere for $3 \mathrm{~min}$ at room temperature. Following bacterial adherence, the wells were gently filled with $200 \mu \mathrm{L}$ of growth media (BHI broth) and incubated for $48 \mathrm{~h}$ at $37{ }^{\circ} \mathrm{C}$ under aerobic conditions to allow biofilm formation.

Following incubation, the supernatant in each well was removed and discarded. Biofilms formed on the tested discs were stained using $200 \mu \mathrm{L}$ crystal violet solution (BD Difco ${ }^{\text {tw }} \mathrm{BBL}^{\mathrm{ma}}, 0.1 \% \mathrm{w} / \mathrm{v}$ ) for $15 \mathrm{~min}$. Excess stain was washed three times with $200 \mu \mathrm{L}$ of phosphate-buffered saline (PBS), followed by destaining with $200 \mu \mathrm{L}$ of acetic acid $(33 \% v / v ; 30 \mathrm{~min})$. The stain eluate was tenfold diluted with PBS and quantified spectrophotometrically using a microplate reader (M.R.C, China, $600 \mathrm{~nm}$. Experiments were performed in six replicates.

\section{Biofilm viability assay}

Enterococcus faecalis (ATCC 51299) biofilms were prepared by placing $20 \mu \mathrm{L}$ of the above tested bacterial suspension (1 OD, $600 \mathrm{~nm}$ ) into each of 96-well microplate, followed by 3-min incubation at room temperature to allow bacterial adherence, following which wells were gently filled with $200 \mu \mathrm{L}$ of growth medium (BHI broth). Microplates were incubated for $48 \mathrm{~h}$ at $37^{\circ} \mathrm{C}$ under aerobic conditions to facilitate biofilm formation.

Following biofilm formation, the supernatant in each well was removed and discarded. Each well was refilled with $100 \mu \mathrm{L}$ saline and the discs (with the tested materials) were placed on top of the grown biofilm, in direct contact for $1 \mathrm{~h}$ at $37{ }^{\circ} \mathrm{C}$ under aerobic conditions.

Following $1 \mathrm{~h}$, the tested discs were removed and biofilms were disrupted and stained using Bacteria Live/ Dead assay (PromoKine). Slides were prepared using wet mount $(10 \mu \mathrm{L})$ of each sample and the bacteria were stained for vitality using DMAO green stain for live bacteria and EthD-III red stain for non-vital ones. The Live/ Dead bacterial ratio was determined using fluorescence microscopy (X1000, L3201LED, MRC) by analyzing digital images using a manual counter of six random fields (320X320 dpi) of the slides prepared from each biofilm. Experiments were performed in six replicates.

\section{Statistical analysis}

To compare the effect of the different quaternary ammonium particles concentrations on the quantity variables, ANOVA was applied with post-hoc pairwise comparisons according to Scheffe and Dunnett. All the tests applied were two-tailed and $p$ value $\leq 0.05$ was considered statistically significant.

\section{Results}

\section{Biofilm formation assay}

The effect of quaternary ammonium particles concentration on de novo biofilm formation is presented in Fig. 1. 


\section{Effect of Quaternary Ammonium Particles Concentration on De-novo $E$. faecalis Biofilm Formation}

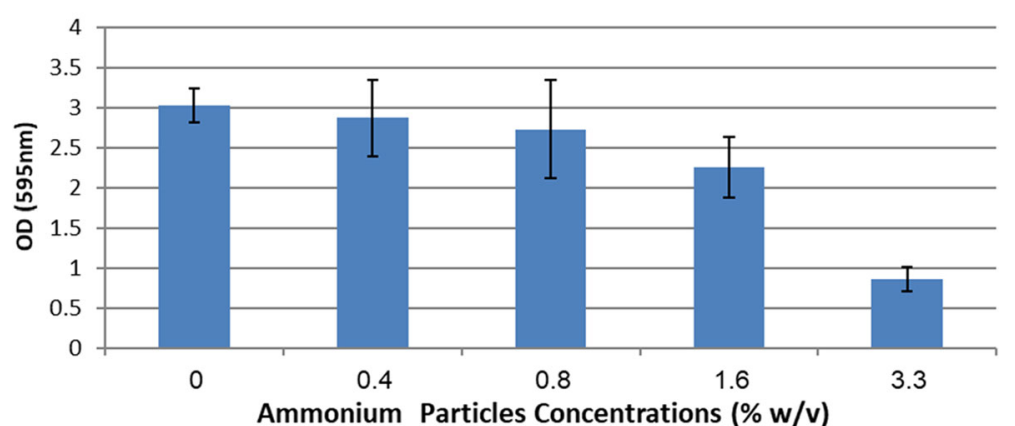

Fig. 1 Mean results $( \pm S D$ ) of de-novo biofilm formation amount on the tested concentrations of the quaternary ammonium incorporated epoxy discs and the control $(0,0.4,0.8,1.6$, and $3.3 \% \mathrm{w} / \mathrm{V})$. Results are expressed as optical density (OD) at $595 \mathrm{~nm}$

Results demonstrated significant reductions in de-novo biofilm formation of 25 and $72 \%$ in the higher quaternary ammonium concentrations of 1.6 and $3.3 \% \mathrm{w} / v$ respectively ( $p<0.001$ for both) as compared to the no-addition control discs. Smaller reductions in de-novo biofilm formation were observed at the lower quaternary ammonium particles concentrations (i.e., 0.4 and $0.8 \% w / v)$; however, these were not statistically significant ( $p=0.309$ and $p=0.215$, respectively).

\section{Biofilm viability assay}

The effect of quaternary ammonium particles concentration on biofilm viability is presented in Fig. 2. Significant reductions in biofilm viability of 20 and $36 \%$ were observed in the higher concentrations of 1.6 and 3.3\% $w / v$ respectively, as compared to the no-addition control discs $(p<0.001$ for both). Lower reductions in biofilm viability were observed at the lower quaternary ammonium particles concentrations (i.e., 0.4 and $0.8 \% w / v$ ); however, they were not statistically significant $(p=0.456$ and $p=0.371$, respectively).

The effect of quaternary ammonium particles concentration on biofilm viability is also demonstrated by fluorescence microscopy imaging (Fig. 3). In the higher concentrations of 1.6 and $3.3 \% \mathrm{w} / \mathrm{v}$, more dead bacteria (dyed red-orange) are observed, as opposed to more live bacteria (dyed green) in the lower concentrations of quaternary ammonium incorporated epoxy discs.

\section{Discussion}

Since 2005, some researchers define apical periodontitis as an intracanal biofilm-induced disease (Nair et al. 2005). Several strategies have been proposed in order to eliminate the residual biofilm, including different

\section{Effect of Quaternary Ammonium Particles Concentration on E. faecalis Biofilm Viability}

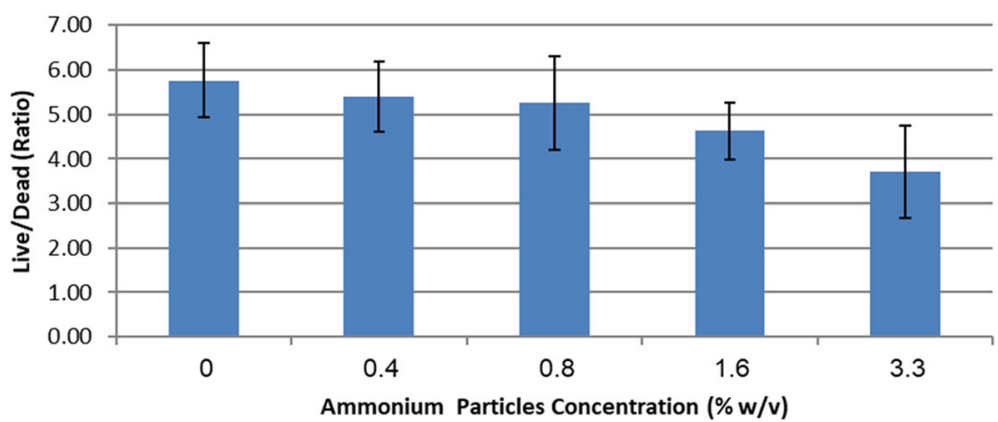

Fig. 2 Mean results $( \pm S D)$ of the effect of various concentrations of quaternary ammonium incorporated epoxy discs and the control $(0,0.4,0.8$, 1.6, and $3.3 \% \mathrm{w} / \mathrm{V}$ ) on biofilm viability. Results are expressed as Live/Dead bacterial ratio 


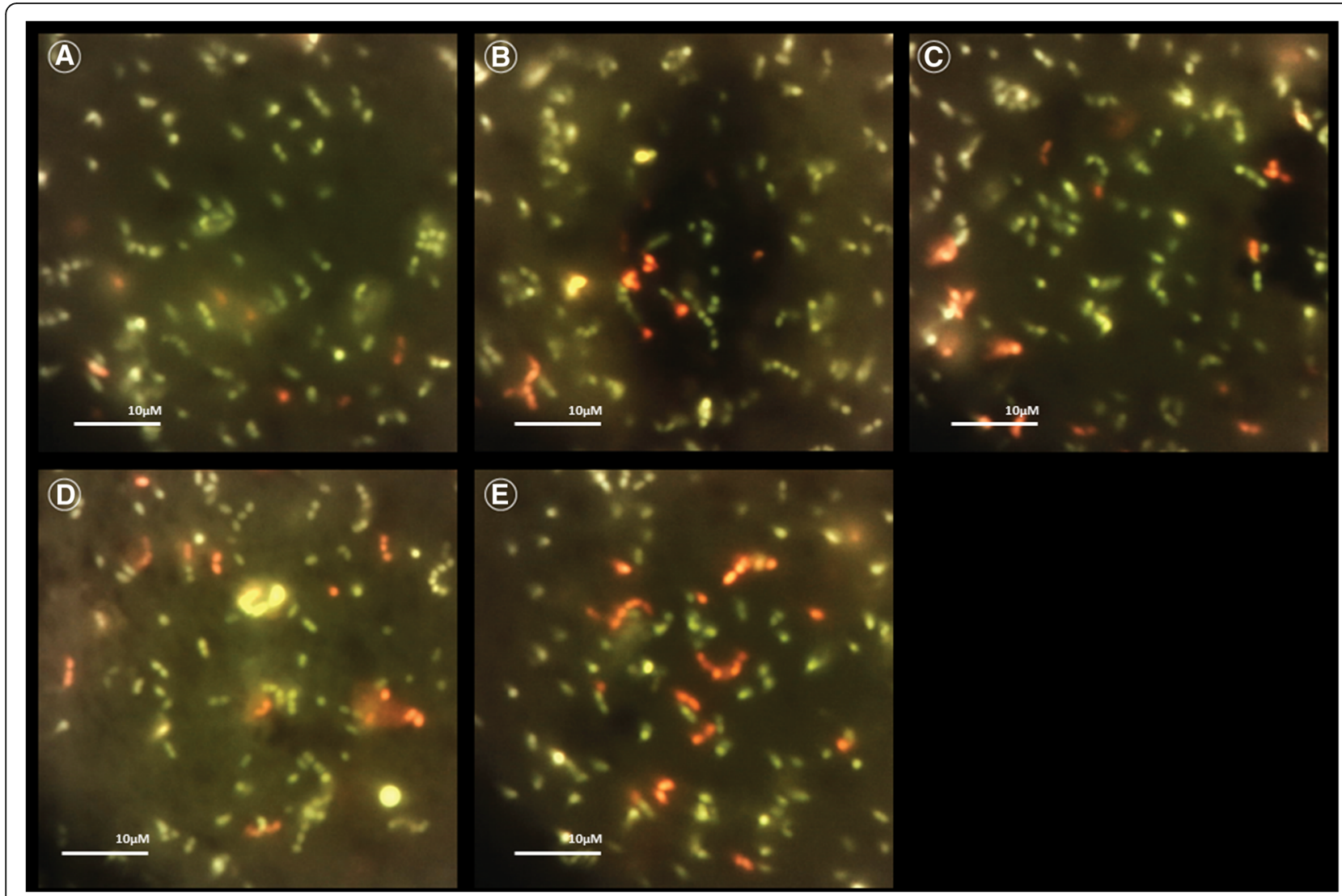

Fig. 3 Fluorescence microscopy images of live (green) and dead (red-orange) bacteria in various concentrations of quaternary ammonium incorporated epoxy discs. a Control group (0\%). b $0.4 \% \mathrm{w} / \mathrm{v}$. c $0.8 \% \mathrm{w} / \mathrm{v}$. d $1.6 \% \mathrm{w} / \mathrm{v}$. e $3.3 \% \mathrm{w} / \mathrm{V}$

instrumental techniques (Peters et al. 2010; Peters 2004), agitation of irrigation ( $\mathrm{Gu}$ et al. 2009), ozone treatment (Cardoso et al. 2008; Huth et al. 2009), direct laser irradiation (Fransson et al. 2013; Sadık et al. 2013), and photodynamic therapy techniques (PDT) (Schlafer et al. 2010; Siqueira and Rôças 2011; de Oliveira et al. 2014).

A new approach of insoluble macromolecular disinfectants has been introduced, which can inactivate the target microorganisms by direct contact without releasing any systemic antibacterial agents (Kenawy et al. 2007). The mechanism is based on the positive charge of the macromolecules which interacts and thus disrupts the negatively charged bacterial membrane. This approach has led to the addition of various nanoparticles, like Chitozan, Ag, and quaternary ammonium polyethyleneimine (QA-PEI), to irrigants and intracanal medications and sealers (Shrestha et al. 2010; Kishen et al. 2008; Allaker 2010; Rai et al. 2012; Wu et al. 2014; Shrestha and Kishen 2014; Chen et al. 2012; Upadya et al. 2011; Rabea et al. 2003) . Nevertheless, no technique has yet been able to completely eliminate the residual biofilm.

Another approach is preventing biofilm formation and/or survival. Experiments with synthetic nanoparticle quaternary ammonium polyethyleneimine (QA-PEI) have shown that their addition to dental materials has prevented biofilm formation on the surfaces of these dental materials (Beyth et al. 2006; Beyth et al. 2008).

One of the reasons of root canal treatment failure is lack of proper coronal sealing (Ray and Trope 1995; Keinan et al. 2011; Heling et al. 2002; Gillen et al. 2011). When the coronal restoration is compromised, a coronal leakage may occur, and the root canal system is usually subjected to bacterial infection (Keinan et al. 2011; Heling et al. 2002; Gillen et al. 2011).

A sealer with antibiofilm properties could have an advantage against residual biofilm in the root canal. The use of nonsoluble antibacterial macromolecules may provide long-term antibiofilm action.

BioSafe ${ }^{\bullet}$ (HM4100, BIOSAFE Inc., Pittsburg, PA, USA) comprises of macromolecules with quaternary ammonium groups. It has FDA approval and is used as an additive to catheters and plastic medical devices for prevention of biofilm formation.

In the present study, BioSafe ${ }^{\circ}$ (HM4100, BIOSAFE Inc., Pittsburg, PA, USA) was added to a new epoxy resin sealer (BJM ROOT CANAL SEALER ${ }^{\circ}$, BJM Laboratories Ltd., Or-Yehuda, Israel). This compound qualifies ISO standard (Solomonov and Itzhak 2017). 
Biosafe ${ }^{\circ}$ incorporated epoxy resin sealer was tested for its in vitro antibacterial effect against existing biofilm, and for its ability to inhibit de-novo biofilm formation. Different macromolecule concentrations were examined in order to find the most efficient one.

The results demonstrated significant reductions in biofilm viability (20 and $36 \%$ ) in the higher Biosafe ${ }^{\circ}$ concentrations (1.6 and $3.3 \% w / v$, respectively). Hence, due to its possible influence on residual Biofilm, Biosafe ${ }^{\circ}$ might enhance the antibacterial effect of the root canal sealer.

The microscopic fluorescence imaging technique has also confirmed the above findings, where in the higher Biosafe $^{\bullet}$ concentrations (1.6 and 3.3\% w/v) more dead bacteria are observed as opposed to the lower ones.

Significant reductions (25 and $72 \%$ ) were also observed in de-novo biofilm formation in the higher concentrations (1.6 and 3.3\% $w / v$ respectively). This might have a potential for use in biofilm prevention. If this effect will be found to be long lasting, this could alter our perception regarding the limitations of the coronal seal, especially when post-endodontic restoration is not completed immediately after the endodontic treatment. Hence, the phenomenon of restoration leakage along the time might have much less clinical consequences.

Clearly, because this is an in-vitro model (monobiofilm and non-canal environment), future research is required in order to test the longevity of the antibiofilm effect, the physical properties of the sealer incorporated with BioSafe ${ }^{\oplus}$ (HM4100, BIOSAFE Inc., Pittsburg, PA, USA), and it is efficacy in the environment of the root canal. Surely, further research is needed to prove clinical efficacy.

\section{Conclusions}

Quaternary ammonium macromolecule incorporated in epoxy root canal sealer discs showed a pronounced reduction of de-novo biofilm formation in the higher concentrations (1.6 and $3.3 \% w / v)$, as well as some antibacterial effect against existing biofilm of Enterococcus faecalis. This may be effective for prevention of de-novo formation of bacterial biofilm in treated root canals.

\section{Abbreviations}

$\mathrm{BHI}$ : Brain heart infusion; OD: Optical density; PBS: Phosphate-buffered saline

\section{Acknowledgements}

Not applicable.

\section{Funding}

The research was funded by BJM Laboratories Ltd. (Or-Yehuda, Israel), by means of providing the tested materials and laboratories equipment.

Availability of data and materials

Please contact author for data requests.

\section{Authors' contributions}

TB drafted the manuscript and assisted in the experiment. NS designed the experiment. RB-NG performed the experiment and edited the manuscript. IT assisted in the experiment. MS drafted the manuscript. All authors read and approved the final manuscript.

\section{Ethics approval and consent to participate}

Not applicable.

\section{Consent for publication}

Not applicable.

Competing interests

The authors declare that they have no competing interests.

\section{Publisher's Note}

Springer Nature remains neutral with regard to jurisdictional claims in published maps and institutional affiliations.

\section{Author details}

${ }^{1}$ Department of Endodontology, Goldschleger School of Dental Medicine, Tel Aviv University, Tel Aviv, Israel. ²Department of Prosthodontics, Goldschleger School of Dental Medicine, Tel Aviv University, Tel Aviv, Israel. ${ }^{3}$ Department of Oral Biology, Goldschleger School of Dental Medicine, Tel Aviv University, Tel Aviv, Israel. ${ }^{4}$ Goldschleger School of Dental Medicine, Tel Aviv University, Tel Aviv, Israel. ${ }^{5}$ The Department of Endodontics, Israel Defense Forces, Medical Corps, Tel Hashomer, Israel. ${ }^{6}$ Qiryat Ono, Israel.

Received: 21 December 2018 Accepted: 15 February 2019

Published online: 26 February 2019

\section{References}

Allaker RP. The use of nanoparticles to control oral biofilm formation. J Dent Res. 2010;89(11):1175-86.

Barros J, Silva MG, Rôças IN, Gonçalves LS, Alves FF, Lopes MA, et al. Antibiofilm effects of endodontic sealers containing quaternary ammonium polyethylenimine nanoparticles. J Endod. 2014;40(8):1167-71.

Beyth N, Houri-Haddad Y, Baraness-Hadar L, Yudovin-Farber I, Domb AJ, Weiss El. Surface antimicrobial activity and biocompatibility of incorporated polyethylenimine nanoparticles. Biomaterials. 2008;29(31):4157-63.

Beyth N, Yudovin-Farber I, Bahir R, Domb AJ, Weiss El. Antibacterial activity of dental composites containing quaternary ammonium polyethylenimine nanoparticles against streptococcus mutans. Biomaterials. 2006;27(21):3995-4002.

Cardoso MG, de Oliveira LD, Koga-Ito CY, Jorge AO. Effectiveness of ozonated water on candida albicans, enterococcus faecalis, and endotoxins in root canals. Oral Surg Oral Med Oral Pathol Oral Radiol Endod. 2008;105(3):e85-91.

Chen CP, Chen CT, Tsai T. Chitosan nanoparticles for antimicrobial photodynamic inactivation: characterization and in vitro investigation. Photochem Photobiol. 2012;88(3):570-6.

Costerton JW, Cheng KJ, Geesey GG, Ladd TI, Nickel JC, Dasgupta M, Marrie TJ. Bacterial biofilms in nature and disease. Annu Rev Microbiol. 1987;41:435-64.

Costerton JW, Lewandowski Z, DeBeer D, Caldwell D, Korber D, James G. Biofilms, the customized microniche. J Bacteriol. 1994;176(8):2137-42.

D'Antonio NN, Rihs JD, Stout JE, Yu VL. Computer keyboard covers impregnated with a novel antimicrobial polymer significantly reduce microbial contamination. Am J Infect Control. 2013;41(4):337-9.

de Oliveira BP, Aguiar CM, Câmara AC. Photodynamic therapy in combating the causative microorganisms from endodontic infections. Eur J Dent. 2014;8(3): 424-30.

Fransson $\mathrm{H}$, Larsson KM, Wolf E. Efficacy of lasers as an adjunct to chemomechanical disinfection of infected root canals: a systematic review. Int Endod J. 2013;46(4):296-307.

Gilbert P, Das J, Foley I. Biofilm susceptibility to antimicrobials. Adv Dent Res. 1997;11(1):160-7.

Gillen BM, Looney SW, Gu LS, Loushine BA, Weller RN, Loushine RJ, et al. Impact of the quality of coronal restoration versus the quality of root canal fillings on success of root canal treatment: a systematic review and meta-analysis. J Endod. 2011;37(7):895-902.

Gu LS, Kim JR, Ling J, Choi KK, Pashley DH, Tay FR. Review of contemporary irrigant agitation techniques and devices. J Endod. 2009;35(6):791-804. 
Heling I, Gorfil C, Slutzky H, Kopolovic K, Zalkind M, Slutzky-Goldberg I. Endodontic failure caused by inadequate restorative procedures: review and treatment recommendations. J Prosthet Dent. 2002;87(6):674-8.

Hülsmann M, Heckendorff M, Lennon A. Chelating agents in root canal treatment: mode of action and indications for their use. Int Endod J. 2003;36(12):810-30.

Huth KC, Quirling M, Maier S, Kamereck K, Alkhayer M, Paschos E, et al. Effectiveness of ozone against endodontopathogenic microorganisms in a root canal biofilm model. Int Endod J. 2009;42(1):3-13.

Kakehashi S, Stanley HR, Fitzgerald R. The exposed germ-free pulp: effects of topical corticosteroid medication and restoration. Oral Surg Oral Med Oral Pathol. 1969;27(1):60-7.

Keinan D, Moshonov J, Smidt A. Is endodontic re-treatment mandatory for every relatively old temporary restoration? A narrative review. J Am Dent Assoc. 2011;142(4):391-6.

Kenawy e-R, Worley SD, Broughton R. The chemistry and applications of antimicrobial polymers: a state-of-the-art review. Biomacromolecules. 2007; 8(5):1359-84.

Kesler Shvero D, Abramovitz I, Zaltsman N, Perez Davidi M, Weiss El, Beyth N. Towards antibacterial endodontic sealers using quaternary ammonium nanoparticles. Int Endod J. 2013;46(8):747-54.

Kishen A, Shi Z, Shrestha A, Neoh KG. An investigation on the antibacterial and antibiofilm efficacy of cationic nanoparticulates for root canal disinfection. J Endod. 2008;34(12):1515-20.

Möller AJ, Fabricius L, Dahlén G, Ohman AE, Heyden G. Influence on periapical tissues of indigenous oral bacteria and necrotic pulp tissue in monkeys. Scand J Dent Res. 1981;89(6):475-84.

Nair PN. Endodontic biofilm, technology and pulpal regenerative therapy: where do we go from here? Int Endod J. 2014;47(11):1003-11.

Nair PN, Henry S, Cano V, Vera J. Microbial status of apical root canal system of human mandibular first molars with primary apical periodontitis after "onevisit" endodontic treatment. Oral Surg Oral Med Oral Pathol Oral Radiol Endod. 2005;99(2):231-52.

Peters OA. Current challenges and concepts in the preparation of root canal systems: a review. J Endod. 2004;30(8):559-67.

Peters OA, Boessler C, Paqué F. Root canal preparation with a novel nickeltitanium instrument evaluated with micro-computed tomography: canal surface preparation over time. J Endod. 2010;36(6):1068-72.

Rabea El, Badawy ME, Stevens CV, Smagghe G, Steurbaut W. Chitosan as antimicrobial agent: applications and mode of action. Biomacromolecules. 2003;4(6):1457-65.

Rai MK, Deshmukh SD, Ingle AP, Gade AK. Silver nanoparticles: the powerful nanoweapon against multidrug-resistant bacteria. J Appl Microbiol. 2012; 112(5):841-52.

Ray HA, Trope M. Periapical status of endodontically treated teeth in relation to the technical quality of the root filling and the coronal restoration. Int Endod J. 1995;28(1):12-8.

Sadık B, Arkan S, Beldüz N, Yaşa Y, Karasoy D, Cehreli M. Effects of laser treatment on endodontic pathogen enterococcus faecalis: a systematic review. Photomed Laser Surg. 2013;31(5):192-200.

Schlafer S, Vaeth M, Hørsted-Bindslev P, Frandsen EV. Endodontic photoactivated disinfection using a conventional light source: an in vitro and ex vivo study. Oral Surg Oral Med Oral Pathol Oral Radiol Endod. 2010;109(4):634-41.

Shrestha A, Kishen A. Antibacterial efficacy of photosensitizer functionalized biopolymeric nanoparticles in the presence of tissue inhibitors in root canal. J Endod. 2014:40(4):566-70.

Shrestha A, Shi Z, Neoh KG, Kishen A. Nanoparticulates for antibiofilm treatment and effect of aging on its antibacterial activity. J Endod. 2010;36(6):1030-5.

Siqueira JF, Rôças IN. Optimising single-visit disinfection with supplementary approaches: a quest for predictability. Aust Endod J. 2011;37(3):92-8.

Solomonov M, Itzhak JB. Evaluating the physical properties of one novel and two well-established epoxy resin-based root canal sealers. Endodontic Practice Today. 2017;1:11(4)

Upadya M, Shrestha A, Kishen A. Role of efflux pump inhibitors on the antibiofilm efficacy of calcium hydroxide, chitosan nanoparticles, and light-activated disinfection. J Endod. 2011;37(10):1422-6.

Vianna ME, Horz HP, Gomes BP, Conrads G. In vivo evaluation of microbial reduction after chemo-mechanical preparation of human root canals containing necrotic pulp tissue. Int Endod J. 2006;39(6):484-92.

Wu D, Fan W, Kishen A, Gutmann JL, Fan B. Evaluation of the antibacterial efficacy of silver nanoparticles against enterococcus faecalis biofilm. J Endod. 2014;40(2):285-90.

\section{Submit your manuscript to a SpringerOpen ${ }^{\circ}$ journal and benefit from:}

- Convenient online submission

- Rigorous peer review

- Open access: articles freely available online

High visibility within the field

- Retaining the copyright to your article

Submit your next manuscript at $\boldsymbol{\nabla}$ springeropen.com 